\title{
Lives uncovered: reflections on encounters with newly arrived Syrians
}

Cite as: CMAJ 2017 March 13;189:E411-2. doi: 10.1503/cmaj.160827

CMAJ Podcasts: article reading at https://soundcloud.com/cmajpodcasts/160827-enc

\section{6}

I sometimes feel I should have my head covered." So shared a colleague at an urban clinic where we see many newcomers from Syria. I can relate - I am often self-conscious about my bare ankles and shoulders as I work in the midsummer heat. Surely Syrians have experience with heat? Indeed, these people, half of them children, have experienced much. Violence, overcrowded living conditions, loss of loved ones, loss of jobs, loss of identity. Displaced like lost luggage.

As health care providers, we get a small glimpse into the effects of this displacement. We are armed with some facts and figures, checklists for vaccinations, weekly news stories. However, this doesn't fully prepare us for patient encounters. At my community health clinic, we share raw stories of first impressions, vaguely aware of our naivety, slightly uncomfortable with our narrow Canadian perspective, knowing that judgment hovers near. We struggle with the clash of cultures. We are puzzled by unfamiliar understandings of illness. We painstakingly decipher unknown medications. We are surprised by remarkable resilience. We feel helpless when communication fails, even with adequate interpreters. We experience the similarities and the differences. Always, we learn.

Our skills of history-taking and assessment are put to the test. When a patient is booked urgently for an assessment of "temper tantrums," I am surprised to see a young man. He reports feeling tense and needing to sleep when the neighbours are noisy. I eventually realize he has some anxiety/ posttraumatic stress disorder issues. A colleague noted that the hands of many women were red and irritated. She discov- ered they commonly use bleach to wash the family's clothes in the sink.

Some Syrians have interesting explanations for problems. Parents of a nine-yearold boy with leg pain insist it is because of an episode of lack of oxygen to his brain. A 15-year-old's height is below the third percentile. Her parents are not concerned: "She doesn't eat very well." A 10-year-old girl has had kidney disease for five years: "If she holds in her urine she gets protein in it." One man thinks he has a deviated nasal septum because of treatment with silver nitrate for epistaxis.

We are intrigued by conditions, especially in children, that are normally the domain of specialists: Sturge-Weber syndrome, rickets, congenital heart disease, retinoblastoma, type 1 diabetes mellitus. A clearly underdeveloped teenage girl likely has Turner syndrome. But we have no reports. An eight-year-old boy has clubbing, cyanosis, a loud heart murmur and a vague history of heart surgery.

We hear sad stories. One man witnessed his cousin being murdered; his head rolling on the floor. A young woman, newly arrived with her parents and younger siblings, complains of intermittent shaking and constant worrying. She refuses to walk to the clinic alone, despite her family's insistence. The story emerges slowly. The family fled Syria when their home was suddenly invaded. Months later, she screams when she sees red liquid on the floor, thinking her family has been

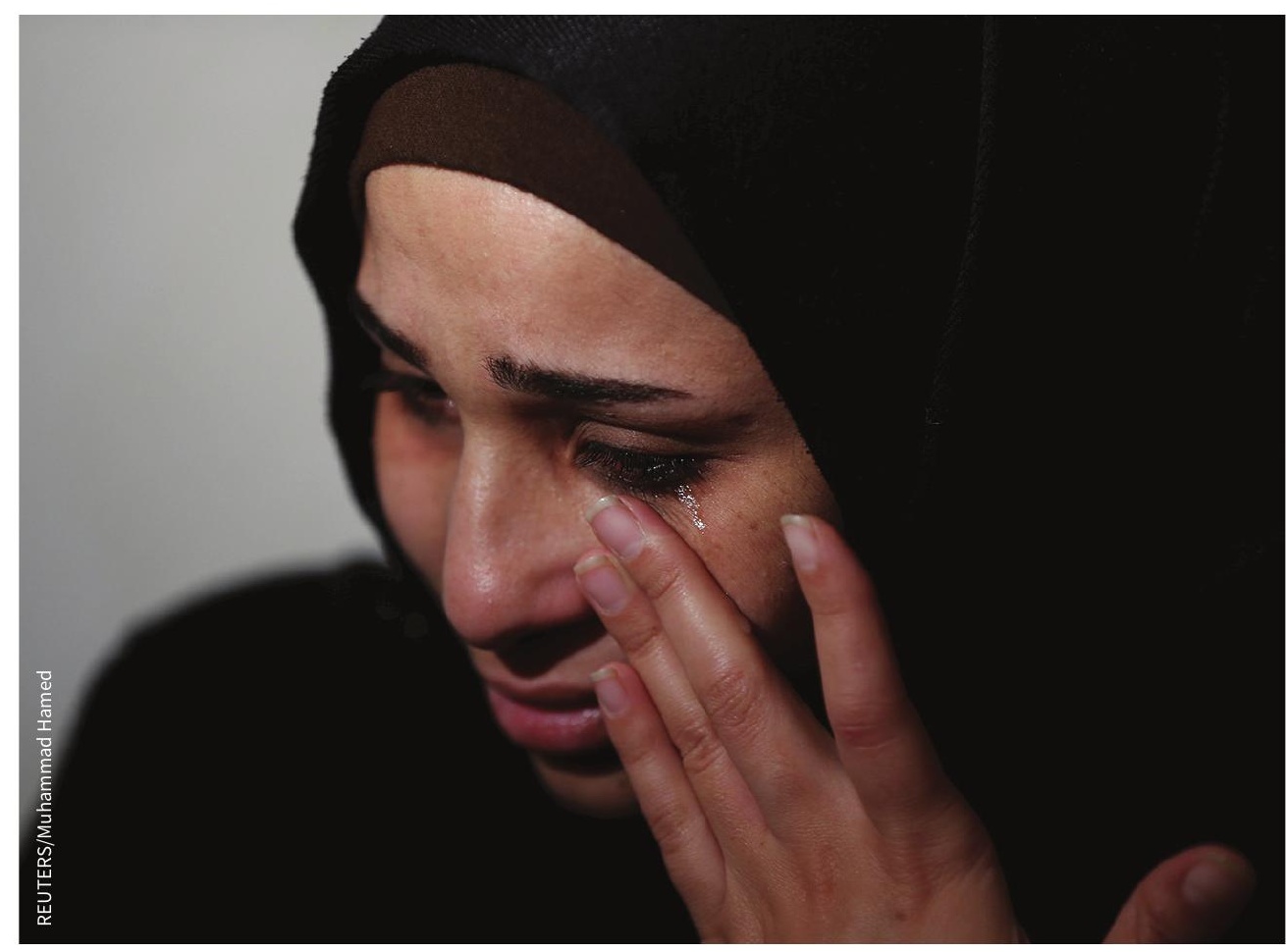


killed. It was only spilled juice. We trust that empathy is translatable.

Yet, we are surprised that mental health problems are not more prevalent. Surely all these people have good reasons to feel hopeless and afraid? Do they not all experience nightmares? Perhaps when one is in survival mode, the focus is on feeding one's children rather than nurturing feelings. We also discover that Syrians have few terms for things like psychological well-being, and little understanding of depression and anxiety. Suffering is an expected part of life. The concept of mental illness is reserved for those with conditions like schizophrenia.

We observe much cultural diversity with respect to gender and family. One woman, married at age 17 after completing grade six, now has four children. However, another woman, unmarried at age 32 , has an advanced degree in physics. One patient refuses a pelvic exam until her husband is informed of the reason and gives permission. One couple is anxious to be referred to a fertility clinic. Would having a child help the family establish roots in Canada? Many other women request contraception - another child would only add stress to their already overstressed lives.

We are touched by the small things. Many people express great appreciation through nods and smiles. A toddler arrives in a cute snowsuit. Except it is spring and really quite warm for Canada. Mom is relieved to be told the snowsuit is unnecessary - diaper changes are now easier. A three-year-old boy, tired of being asked to do silly movements (actually part of a musculoskeletal exam), clearly refuses further requests. There are other amusing moments. I advise a man with anxiety to decrease his coffee consumption (15 cups a day); he informs me he has, because Canadian coffee is bad.

We worry about broader, long-term issues relating to identity, which are often connected to career. Many occupations are not easily transferrable to Canada. One man was a tailor - an outdated service in North America. Many people worked in agriculture, but farming is culture- and climatedependent. One man operated a successful business in Syria. His experience in sales is clear in the tone of his speech. But he is embarrassed that he needs an interpreter; trapped by his inability to speak English. We sense the helplessness.
As we see the person behind the medical concern, we connect with our own humanness. No, we do not need to cover our own heads, but we can relate on other levels. We feel renewed gratitude for the relative security offered to Canadian citizens. We wonder what the longterm picture of blended cultures will look like. What other stories will be uncovered?

\section{E. Janet Warren BSC MD}

Family physician, Hamilton Urban Core Community Health Centre, Hamilton, Ont.

This article has been peer reviewed.

Patient details have been changed to protect confidentiality.

"Imagination is more important than knowledge. For knowledge is limited, whereas imagination embraces the entire world, stimulating progress, giving birth to evolution." - Albert Einstein 